\title{
QUALIDADE DE POLPA DE PÊSSEGOS PRESERVADA POR MÉTODOS COMBINADOS
}

\section{PEACHES \\ PULP QUALITY PRESERVED BY AGREED METHODS}

\author{
Paula Ferreira de Araújo ; Rosane da Silva Rodrigues ${ }^{2}$; Ana Paula Duarte ${ }^{3}$ \\ ${ }^{1}$ Federal University of Pelotas - UFPel - Pelotas/RS - Brasil paulaufpel@pop.com.br \\ ${ }^{2}$ Federal University of Pelotas - UFPel - Pelotas/RS - Brasil rosane.rodrigues@ufpel.tche.br \\ ${ }^{3}$ Federal Unversity of Pelotas - UFPel - Pelotas/RS - Brasil anapaulaufpel@gmail.com
}

\begin{abstract}
Resumo
Este trabalho teve por objetivo verificar a qualidade de polpa de pêssegos (Prunus pérsica) preservada por métodos combinados e armazenada a temperatura ambiente, produzida por empresa localizada na região de Pelotas-RS. A região caracteriza-se pela cultura do pessegueiro cujos frutos são destinados quase que na sua totalidade ao aproveitamento industrial. Foram coletadas amostras de polpa durante 6 meses, contados a partir do terceiro mês do processamento inicial da empresa, quando a mesma teve início à utilização do material, no período considerado como entressafra da fruta, nas quais determinou-se $\mathrm{pH}$, acidez total, sólidos solúveis, açúcares totais, redutores e não-redutores, teor de pectina, viscosidade aparente na água de armazenamento da polpa e na polpa drenada-triturada, além da contagem de bolores e leveduras. De acordo com os resultados obtidos durante a pesquisa observou-se que a polpa de pêssegos preservada por métodos combinados e armazenada a temperatura ambiente manteve-se estável microbiologicamente até 9 meses de armazenamento, mostrando, contudo diferenças marcantes nas suas características físico-químicas.
\end{abstract}

Palavras-chave: polpa de pêssego; preservação; métodos combinados.

\section{Introdução}

O Rio Grande do Sul é considerado um dos maiores estados produtores de pêssegos (Prunus pérsica) do Brasil. Sua produção destina-se tanto para a indústria como para o consumo in natura, sendo o sul do estado tipicamente um produtor de frutos para a industrialização (PROTAS e MADAIL, 2003).

No município de Pelotas localizam-se as maiores indústrias de conserva de pêssegos, sendo industrializada mais de $90 \%$ da produção brasileira. A maioria dessas indústrias ainda é caracterizada como de pequeno porte e, além da conserva de pêssegos, processada artesanalmente, 
utilizam a fruta na elaboração de outros produtos como polpas, geléias e doces em massa (PROTAS e MADAIL, 2003).

O pêssego tem apenas uma safra por ano, com oferta a partir do final de outubro e início de novembro até a primeira quinzena de fevereiro, concentrando-se a maior parte da produção nos meses de dezembro e janeiro. Isto dificulta a dinâmica produtiva do setor, a alocação de mão-deobra, o capital de giro, assim como outros aspectos envolvidos na industrialização (MEDEIROS e RASEIRA, 1998).

A disponibilização de matérias-primas sazonais, a exemplo do pêssego, para utilização industrial, tem sido tradicionalmente realizada através da manutenção sob congelamento da fruta inteira ou pré-processada, como polpas submetidas a tratamento térmico ou químico, ou envasadas. Estas técnicas de conservação acarretam um custo muito alto de manutenção, principalmente quando se utiliza cadeia de frio e investimento em embalagens e energia, assim como quando se aplica esterilização ou secagem.

A preservação de alimentos por métodos combinados tem se mostrado uma alternativa aos métodos tradicionais de conservação, muitas vezes reduzindo o custo relativo e permitindo obter maior eficiência e menor rigor comparativamente a aplicação de um método isolado (DAZA et al., 1991). Consiste na reunião adequada de vários parâmetros como, tratamento térmico brando ou moderado, leve redução da atividade de água (Aa), redução de $\mathrm{pH}$, adição simples ou combinada de agentes químicos e outros (CHIRIFE e FAVETO, 1992; ALZAMORA et al., 1993; WELTICHANES et al., 1997).

Na região de Pelotas, o armazenamento de frutas por métodos combinados, com destaque para o pêssego, tem sido largamente utilizado. A conservação das frutas na forma de polpa triturada ou em pedaços/metades em bombonas plásticas, juntamente com a adição de conservante químico, sob condições ambientais, são as alternativas utilizadas por muitos estabelecimentos, particularmente os de pequeno porte, possibilitando a disponibilização de matéria-prima para processamento ao longo do ano.

Embora o método venha mostrando relativa eficiência na manutenção da estabilidade do produto por um período de tempo considerável, da ordem de 8 a 10 meses, as condições técnicooperacionais da maioria dos estabelecimentos não garante uma padronização na aplicação dos procedimentos. Este fato, associado a provável desuniformidade da matéria-prima, parecem refletir na qualidade final da mesma e também dos produtos elaborados a partir destas polpas.

Através deste trabalho objetivou-se avaliar a qualidade de polpa de pêssegos em metades preservada por métodos combinados e armazenada à temperatura ambiente, produzida por indústria localizada na região de Pelotas-RS. 


\section{Material e Métodos}

Polpas de pêssegos conservadas por métodos combinados foram cedidas por indústria de pequeno porte localizada na região de Pelotas - RS. Segundo informações da empresa, as polpas foram obtidas a partir de pêssegos da safra 2004/2005, colhidos entre os meses de janeiro e fevereiro na região de Pelotas - RS. As mesmas foram processadas quão logo as frutas eram recebidas, muitas vezes em diferentes dias, a cada lote de matéria-prima entregue na empresa, utilizando como critério de seleção, o estádio de maturação das frutas, indicado pela coloração amarelo/avermelhada da casca.

Os pêssegos, após descascamento e descaroçamento, foram cortados em metades e submetidos aos métodos combinados de conservação: tratamento térmico uso de conservante químico e hermeticidade. Segundo este trinômio as polpas foram imersas em água, tratadas termicamente, adicionadas de conservante químico (benzoato e sorbato de sódio) e posteriormente embaladas à quente juntamente com a água de imersão, com posterior fechamento em sistema hermético. Durante o armazenamento as mesmas permaneceram em bombonas de polietileno de alta densidade, estocadas em lugar seco e arejado, à temperatura ambiente.

A verificação da qualidade das polpas foi acompanhada durante 6 meses, contados a partir do terceiro mês do processamento inicial, quando a empresa começou a utilizar o material para o processamento industrial, no período considerado como entressafra da fruta. Amostras das polpas foram coletadas diretamente na indústria, durante o período de abril a setembro/2005, na primeira quinzena de cada mês. As coletas foram realizadas sempre no momento da abertura dos recipientes para utilização da matéria-prima no processamento industrial, utilizando-se frascos de vidro devidamente esterilizados. O material era imediatamente transportado aos Laboratórios de Controle de Qualidade e de Microbiologia do Departamento de Ciência dos Alimentos da Universidade Federal de Pelotas para análise, sendo as amostras de polpa/metades drenadas da água de armazenamento, trituradas, homogeneizadas e avaliadas quanto às suas características físicoquímicas e microbiológicas.

Determinou-se, em triplicata: $\mathrm{pH}$, acidez total (\% ácido cítrico), sólidos solúveis ( $\left.{ }^{\circ} \mathrm{Brix}\right)$, açúcares totais ( $\%$ glicose), redutores (\% glicose), não-redutores (\% sacarose) e teor de pectina (\% pectato de cálcio), de acordo com metodologia descrita pela AOAC (1995). Determinou-se também a viscosidade aparente em Haake Viscosimeter, nas condições de $20^{\circ} \mathrm{C}, 100 \mathrm{RPM}$, tempo de 30 segundos e spindle L1 e L3, respectivamente na água de armazenamento da polpa e na polpa drenada (triturada). 
A avaliação microbiológica consistiu na contagem de bolores e leveduras utilizando-se a técnica de plaqueamento em superfície segundo a American Public Health Association (2001), com os resultados expressos em UFC. $\mathrm{g}^{-1}$ de polpa analisada.

Os resultados foram analisados estatisticamente utilizando-se análise de variância (ANOVA), teste F e aplicando-se o teste de Tukey com nível de significância de 5\% para comparação das médias.

\section{Resultados e Discussão}

Os resultados das determinações físico-químicas realizadas nas polpas de pêssegos preservadas por métodos combinados e armazenadas à temperatura ambiente encontram-se nas Tabelas 1 e 2.

Tabela 1 - Teor de sólidos solúveis e açúcares de polpas de pêssegos em metades preservadas por métodos combinados, à temperatura ambiente, a partir de 3 meses de armazenamento.

\begin{tabular}{lcccc}
\hline $\begin{array}{c}\text { Período de coleta } \\
(\text { mês })\end{array}$ & $\begin{array}{c}\text { Sólidos solúveis } \\
\left({ }^{\circ} \text { Brix }\right)\end{array}$ & $\begin{array}{c}\text { Açúcares Totais } \\
(\% \text { glicose })\end{array}$ & $\begin{array}{c}\text { Açúcares Redutores } \\
(\% \text { glicose })\end{array}$ & $\begin{array}{c}\text { Açúcares Não- } \\
\text { redutores } \\
(\% \text { sacarose })\end{array}$ \\
\hline 4 (abril) & $6,0 \pm 0,00^{\mathrm{a}}$ & $8,5 \pm 0,25^{\mathrm{a}}$ & $2,6 \pm 0,05^{\mathrm{d}}$ & $5,8 \pm 0,29^{\mathrm{a}}$ \\
5 (maio) & $6,5 \pm 0,00^{\mathrm{a}}$ & $6,8 \pm 0,14^{\mathrm{b}}$ & $2,2 \pm 0,08^{\mathrm{e}}$ & $6,6 \pm 0,15^{\mathrm{d}}$ \\
6 (junho) & $4,6 \pm 0,00^{\mathrm{a}}$ & $5,0 \pm 0,26^{\mathrm{c}}$ & $2,7 \pm 0,03^{\mathrm{d}}$ & $2,2 \pm 0,23^{\mathrm{c}}$ \\
7 (julho) & $4,5 \pm 0,00^{\mathrm{a}}$ & $4,7 \pm 0,07^{\mathrm{c}}$ & $2,9 \pm 0,02^{\mathrm{c}}$ & $1,7 \pm 0,05^{\mathrm{c}}$ \\
8 (agosto) & $4,8 \pm 0,00^{\mathrm{a}}$ & $6,4 \pm 0,31^{\mathrm{b}}$ & $3,5 \pm 0,11^{\mathrm{b}}$ & $2,9 \pm 0,19^{\mathrm{b}}$ \\
9 (setembro) & $5,2 \pm 0,00^{\mathrm{a}}$ & $6,8 \pm 0,02^{\mathrm{b}}$ & $3,8 \pm 0,02^{\mathrm{a}}$ & $3,0 \pm 0,03^{\mathrm{b}}$ \\
\hline
\end{tabular}

* Os valores representam as médias de 3 repetições \pm desvio padrão;

**Letras distintas na mesma coluna indicam diferença significativa pelo teste de Tukey, em nível de 5\% de probabilidade.

Tabela 2 - Teores de pectina e acidez, pH e viscosidade aparente de polpas de pêssegos em metades preservadas por métodos combinados, à temperatura ambiente, a partir de 3 meses de armazenamento.

\begin{tabular}{|c|c|c|c|c|c|}
\hline $\begin{array}{l}\text { Período da } \\
\text { coleta (mês) }\end{array}$ & $\begin{array}{l}\text { Acidez total } \\
\text { (\% de ácido } \\
\text { cítrico })\end{array}$ & $\mathrm{pH}$ & $\begin{array}{l}\text { Pectina }(\% \text { de } \\
\text { pectato de } \\
\text { Cálcio }) \\
\end{array}$ & $\begin{array}{l}\text { Viscosidade aparente } \\
\text { da fruta drenada- } \\
\text { triturada (mPas) }\end{array}$ & $\begin{array}{l}\text { Viscosidade aparente da } \\
\text { água de armazenamento } \\
\text { (mPas) }\end{array}$ \\
\hline 4 (abril) & $0,42 \pm 0,00^{b}$ & $3,44 \pm 0,00^{\mathrm{a}}$ & $0,07 \pm 0,00^{b}$ & $73,3 \pm 2,25^{\mathrm{a}}$ & $27,4 \pm 0,13^{\mathrm{a}}$ \\
\hline 5 (maio) & $0,47 \pm 0,00^{\mathrm{a}}$ & $3,81 \pm 0,00^{\mathrm{a}}$ & $0,06 \pm 0,00^{\mathrm{c}}$ & $52,8 \pm 2,70^{b}$ & $19,3 \pm 0,57 \quad \mathrm{~d}$ \\
\hline 6 (junho) & $0,26 \pm 0,00$ & $4,07 \pm 0,00^{\mathrm{a}}$ & - & $46,7 \pm 0,40^{b}$ & $20,5 \pm 0,68 d$ \\
\hline 7 (julho) & $0,38 \pm 0,00^{\mathrm{c}}$ & $3,72 \pm 0,00^{\mathrm{a}}$ & $0,05 \pm 0,00^{\mathrm{c}}$ & $38,7 \pm 0,23$ & $17,3 \pm 0,28 \quad$ e \\
\hline 8 (agosto) & $0,35 \pm 0,00 \quad \mathrm{~d}$ & $3,78 \pm 0,00^{\mathrm{a}}$ & $0,01 \pm 0,00^{\mathrm{a}}$ & $71,3 \pm 5,01^{\mathrm{a}}$ & $23,3 \pm 0,50^{\mathrm{c}}$ \\
\hline 9 (setembro) & $0,35 \pm 0,00^{\mathrm{d}}$ & $3,74 \pm 0,00^{\mathrm{a}}$ & $0,05 \pm 0,00^{\mathrm{c}}$ & $53,6 \pm 2,17^{b}$ & $25,3 \pm 0,46^{b}$ \\
\hline
\end{tabular}

* Os valores representam as médias de 3 repetições \pm desvio padrão;

**Letras distintas na mesma coluna indicam diferença significativa pelo teste de Tukey, em nível de 5\% de probabilidade.

*** (-) não determinado. 
Verifica-se na Tabela 1, embora não significativa, uma pequena variação no teor de sólidos solúveis nas 6 polpas analisadas, o que pode ter ocorrido em função do grau de maturação desuniforme da fruta no momento do seu processamento. Segundo Lovatel et al. (2004), as frutas ao chegarem à indústria são classificadas conforme seu tamanho e integridade física, sendo as maiores, as mais firmes e aquelas sem manchas ou defeitos as utilizadas na produção de compotas e o restante na produção de polpa para posteriormente ser utilizada na elaboração de outros produtos como doce em massa, geléia e outros. Com isso a probabilidade de serem misturadas, numa mesma bombona, várias frutas em diferentes estádios de maturação (e, portanto diferentes teores de sólidos solúveis), é muito grande. Apesar de não serem significativas, conforme pode ser evidenciado na análise estatística realizada, mesmo assim essas diferenças devem ser levadas em consideração, pois podem influenciar diretamente na qualidade dos produtos confeccionados com a polpa.

Pequenas variações são evidenciadas nos teores de açúcares redutores e não-redutores, respectivamente, de um mês para outro, em abril de 30:70, em maio de 32:97, junho de 55:45, julho de 62:36, agosto de 55:45 e setembro de 56:44. Conforme Alexandre et al. (2004) estas variações podem ter sido em função do conservante utilizado, pois em seu estudo sobre a conservação do açaí pela tecnologia de obstáculos observaram que nas formulações que continham menores teores de conservante, os teores de sacarose hidrolisada (e, portanto de açúcares redutores) eram maiores, sendo o contrário também verdadeiro. Entretanto pode ser provável que as variações em açúcares observadas neste estudo tenham ocorrido também devido aos diferentes estádios de maturação que as frutas apresentavam no momento do envase e também aos tempos diferenciados de armazenamento entre as polpas avaliadas.

As polpas processadas apresentaram significativa $(\mathrm{p} \leq 0,05)$ variação de acidez titulável e $\mathrm{pH}$, com relativo comportamento inverso como era esperado. A acidez é um importante parâmetro na apreciação do estado de conservação de um produto alimentício. Geralmente um processo de decomposição do alimento, seja por hidrólise, oxidação ou fermentação, altera quase sempre a concentração dos íons de hidrogênio, e por conseqüência sua acidez (Oliveira et al., 1999). Entretanto, tem-se a possibilidade desta variação ter se dado em função de algum problema operacional ocorrido no momento da adição do conservante utilizado na preservação da polpa. Deve-se também levar em consideração o fato de a relação água/polpa dentro das bombonas de armazenamento provavelmente não ser sempre a mesma, a desuniformidade da matéria-prima processada e o fato de que as frutas não foram todas processadas no mesmo dia, fazendo com que algumas tenham maior ou menor tempo de armazenamento. De acordo com Alexandre et al. (2004), o teor de acidez das frutas diminui conforme o aumento da concentração do conservante no meio.

As avaliações também mostram um declínio no percentual de substâncias pécticas das polpas armazenadas juntamente com um abaixamento da viscosidade aparente. Roe e Bruemmer 
(1981) observaram que o amolecimento das frutas, indicado por uma queda da resistência à força de cisalhamento, era acompanhado por um rápido declínio da quantidade total de substâncias pécticas. Segundo esses autores, uma das substâncias, a pectina solúvel, está ligada estruturalmente à parede celular e o amolecimento da polpa seria então causado pela degradação dessas substâncias, o que pode ter ocorrido em função da quantidade de conservante utilizado ou até mesmo devido ao tempo demasiado de armazenamento.

Além das determinações citadas na metodologia de avaliação, embora não tenha sido mensurada objetivamente, a avaliação da cor das polpas merece ser comentada, tendo em vista a acentuada alteração observada. Algumas polpas apresentaram-se mais escuras, o que pode ser fundamentado em um maior índice de oxidação sofrido pela fruta durante o processamento de envase e/ou por motivos externos durante o armazenamento das bombonas. As reações de escurecimento não-enzimático em certas condições podem formar coloração e flavor indesejáveis e alterar a qualidade do alimento durante o processamento e armazenamento, sendo as reações de oxidação química a principal causa do escurecimento desenvolvido durante o aquecimento e armazenamento prolongados do produto (ARAÚJO, 2004). Segundo Jackix (1988), fatores externos como movimentação das bombonas, abertura e fechamento das mesmas, assim como danos na selagem da tampa não são desejados quando se trabalha com produtos armazenados hermeticamente, pois podem propiciar a entrada de oxigênio para o interior do recipiente e com isso desencadear processos de oxidação.

Os resultados das avaliações microbiológicas indicaram que as polpas analisadas não apresentaram, em nenhum momento, crescimento de bolores e leveduras, apresentando sempre resultados <1x10UFC.g ${ }^{-1}$ de polpa analisada, encontrando-se de acordo com os padrões de identidade e qualidade para polpa de frutas citados na Instrução Normativa $n^{0} 1$ de 07 de janeiro de 2000 do Ministério da Agricultura e do Abastecimento (BRASIL, 2000). Esse resultado vem comprovar a eficiência do conservante e da técnica de armazenamento utilizada, uma vez que foram eficazes para garantir a estabilidade microbiológica da polpa de pêssegos armazenada à temperatura ambiente.

Os resultados das avaliações em polpas de pêssegos armazenadas sob condições herméticas e à temperatura ambiente mostraram que estas polpas apresentaram estabilidade microbiológica até 270 dias de armazenamento, apresentando, contudo, modificações consideráveis nas suas características físico-químicas principalmente quanto aos teores de açúcares, acidez e viscosidade aparente. Estas diferenças, embora não comprometam a estabilidade das polpas, devem ser consideradas, pois podem ser limitantes na utilização deste material para o processamento subseqüente, podendo comprometer a qualidade dos produtos confeccionados a partir deste. 
Cabe ressaltar que esta técnica mostra-se efetiva na garantia de disponibilização de pêssegos na entressafra para uso industrial, principalmente para empresas de pequeno e médio porte. Evidencia-se, contudo, possibilidade de potencial melhoria da qualidade e padronização das polpas através do estabelecimento de parâmetros preliminares ao processamento, particularmente aqueles relacionados à caracterização e uniformização da matéria-prima a ser armazenada.

\title{
4. Conclusão
}

Polpas de pêssegos preservadas por métodos combinados e armazenadas a temperatura ambiente, produzidas por indústria localizada na região de Pelotas-RS, apresentaram-se estáveis microbiologicamente até 9 meses de armazenamento, mostrando, contudo diferenças marcantes nas características físico-químicas avaliadas.

\begin{abstract}
The aim of this word is to verify the peaches (Prunus pérsica) pulp quality preserved by agreed and stored methods at environment temperature produced by company in Pelotas/RS. The region is characterized by the peach-tree culture whose fruit are almost all destined to industry. Pulp samples were collected for six months, counted from the third month of the initial processing when the company began using the material at the period considered as time between harvest, in which the $\mathrm{pH}$, total acidity, soluble solids, total sugars, reducers and not reducers, pectin content, apparent viscosity in the pulp keeping water and the triturated drained pulp, were determined besides the moulds and yeasts counting. According to the obtained results during the research the peaches pulp quality preserved by agreed and stored methods and at environment temperature observed was microbiologically stable up to a nine months keeping showing remarkable differences in its physicist-chemical characteristics.
\end{abstract}

Key-words: peaches pulp; preservation; agreed methods.

\section{Referências}

ALEXANDRE, D.; CUNHA, R.L.; HUBINGER, M.D. Conservação do açaí pela tecnologia de obstáculos. Revista Ciência e Tecnologia de Alimentos, Campinas, v.24, n.1, p.114-119, 2004.

ALZAMORA, et al.; Application of Combined Methods Technology im Minimally processed Fruits. Food Research International. v.26, n.2, p. 125-130, 1993.

AMERICAN PUBLIC HEALTH ASSOCIATION. Compendium of methods for the microbiological examination of foods. 4. ed. Washington, 676p, 2001.

AOAC - Association of Afficial Analytical Chemists; Official methods of analyses of the Association of Official Analytical Chemists; 12 ed.; Horwitz; Washington; 1995.

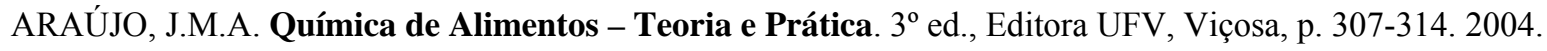

BRASIL. Ministério da Agricultura e do Abastecimento. Instrução Normativa $\mathrm{n}^{\circ} 1$ de 07 de janeiro de 2000. Aprova regulamento técnico geral para fixação dos padrões de identidade e qualidade para polpa de frutas (Anexo 1). Diário

Oficial da República Federativa do Brasil, Brasília, 10 de janeiro de 2000. Seção 1 
CHIRIFE, J.; FAVETO, G.J. Some physico-chemical basis of food preservation by combined methods. Food Research International. v.25, n.5, p. 389-396, 1992.

DAZA, M.S.; VILLEGAS, Y.; MARTINEX, A. Minimal water activity for growth of Listeria monocytogenes as affected by solute and temperature. International Journal Microbiological. v.14, p. 333-337, 1991.

JACKIX, M.H. Doces, geléias e frutas em calda. Editora da Unicamp, Campinas, 172p, 1988.

LOVATEL, J.L.; COSTANZI, A.R.; CAPELLI, R. Processamento de frutas e hortaliças. Caxias do Sul, RS: Educs, p. 93-96, 2004.

MEDEIROS, C.A.B.; RASEIRA, M. do C.; A Cultura do pessegueiro; Embrapa - SPI; Brasília; 350 p, 1998.

OLIVEIRA, M.E.B. de; BASTOS, M. do S.R.; FEITOSA, T.; BRANCO, M.A. de A.C.; SILVA, M. das G.G. da. Avaliação de parâmetros de qualidade físico-químicos de polpas congeladas de acerola, cajá e caju. Revista Ciência e Tecnologia de Alimentos, v.19, n.3, Campinas, 1999.

PROTAS, J.F. da S.; MADAIL, J.C.M. Características econômicas e sociais da produção de pêssego no Rio Grande do Sul. Pelotas: Embrapa - CPACT; 2003.

ROE, B.; BRUEMMER, J.H. Changes in pectic substances and enzymes during ripening and storage of "Keitt” mangos. Journal of Foods Science, v. 46, n. 1, p. 186-189, 1981.

WELTI-CHANES, J.; VERGARA-BALDERAS, F.; LOPEZ-MALO, A. Minimally processed foods: state of art and future. In: FITO, P.; ORTGEA-RODRIGUEZ, E.; BORBOSA-CANOVAS, G.V. (Eds.). Food Engineering 2000. New York: Chapman \& Hall, 1997. Cap. 11.

\section{Dados completos de todos os autores:}

Nome completo: Paula Ferreira de Araújo

Filiação institucional: Universidade Federal de Pelotas

Departamento: Ciência dos Alimentos

Função ou cargo ocupado: Aluna Mestranda em Ciência e Tecnologia Agroindustrial

Endereço completo para correspondência (bairro, cidade, estado, país e CEP): Universidade Federal de Pelotas, Campus Universitário, s/n ${ }^{\circ}$, Caixa Postal 354, Departamento de Ciência dos Alimentos Pelotas/RS - Brasil - CEP: 96010-900

Telefones para contato: (53) 32715631 (53) 91642812

e-mail: paulaufpel@pop.com.br

Nome completo: Ana Paula Duarte

Filiação institucional: Universidade Federal de Pelotas

Departamento: Ciência dos Alimentos

Função ou cargo ocupado: Aluna de graduação do curso de Bacharelado em Química de Alimentos Endereço completo para correspondência (bairro, cidade, estado, país e CEP): Universidade Federal de Pelotas, Campus Universitário, s/nº Caixa Postal 354, Departamento de Ciência dos Alimentos Pelotas/RS - Brasil - CEP: 96010-900

Telefones para contato: (53) 32274695

e-mail: anapaulaufpel@gmail.com 
Nome completo: Rosane da Silva Rodrigues

Filiação institucional: Universidade Federal de Pelotas

Departamento: Ciência dos Alimentos

Função ou cargo ocupado: Professora Doutora do Curso de Bacharelado em Química de Alimentos Endereço completo para correspondência (bairro, cidade, estado, país e CEP): Universidade Federal de Pelotas, Campus Universitário, s/nº Caixa Postal 354, Departamento de Ciência dos Alimentos Pelotas/RS - Brasil - CEP: 96010-900

Telefones para contato: (53) 32757285

e-mail: rosane.rodrigues@ufpel.tche.br 